225 AN ORAL, SELECTIVE INHIBITOR OF TYROSINE KINASE 2, BMS-986165, IMPROVES MOLECULAR, CELLULAR, AND CLINICAL BIOMARKERS ASSOCIATED WITH EFFICACY IN MODERATE TO SEVERE PSORIASIS

${ }^{1}$ Ian Catlett ${ }^{*},{ }^{1}$ Sarah Hu, ${ }^{1}$ Subhashis Banerjee, ${ }^{2}$ Kenneth Gordon, ${ }^{3}$ James Krueger. ${ }^{1}$ BristolMyers Squibb; ${ }^{2}$ Medical College of Wisconsin; ${ }^{3}$ Rockefeller University Hospital, The Rockefeller University

\subsection{6/lupus-2019-Ism.225}

Background Psoriasis, a chronic immune-mediated inflammatory disease dependent upon the interleukin (IL)-23/TH17 pathway, is thought to be initiated through plasmacytoid dendritic cell activation and induction of type I interferons. BMS-986165 is a novel tyrosine kinase 2 (TYK2) inhibitor that blocks signal transduction of IL-23, IL-12, and type I interferons. BMS-986165 selectivity for TYK2, compared with Janus kinases (JAKs) 13, is driven by binding to its pseudokinase domain, rather than the conserved kinase domain.

Methods BMS-986165 was evaluated in a randomized, placebo-controlled, dose-ranging trial in 267 patients with moderate to severe psoriasis. Dose- and time-dependent effects on laboratory parameters indicative of non-selective inhibition of JAKs 13 were assessed. In an optional substudy, 37 patients provided biopsies, which were assessed from healthyappearing skin on Day 1 and from lesional skin on Days 1, 15 , and 85 for changes in the IL-23, IL-12, and type I interferon pathways by QRTPCR, RNA sequencing, and immunohistochemistry.

Results All BMS-986165 treatment groups, except $3 \mathrm{mg}$ every other day (QOD), achieved superiority versus placebo in the proportion of patients achieving Psoriasis Area and Severity Index 75 after 12 weeks of treatment (primary endpoint): $3 \mathrm{mg}$ QOD, 9.1\%; $3 \mathrm{mg}$ daily (QD), 38.6\%; $3 \mathrm{mg}$ twice daily (BID), 68.9\%; $6 \mathrm{mg} \mathrm{BID}, 66.7 \%$; and $12 \mathrm{mg} \mathrm{QD}$, $75.0 \%$ vs $6.7 \%$ with placebo. Mean levels of factors impacted with JAK 13 inhibition, including hemoglobin, total cholesterol, neutrophils, platelets, total lymphocytes, natural killer, and B cells, were not affected by BMS-986165. Markers of the IL-23 pathway including IL-17(A/F), S100A8/ 9, IL-22, and -defensin returned to non-lesion levels dosedependently. Interferon and IL-12 pathway genes were normalized; keratinocyte dysregulation markers keratin-16 and 10 , and late cornified envelope genes, returned toward nonlesion levels with effective doses.

Conclusions Clinical efficacy with BMS-986165 was associated with decreases in IL-23/TH17 and interferon pathway markers. TYK2 selectivity was confirmed by lack of effect on clinical biomarkers of JAK 13 inhibition. BMS-986165 has promising efficacy in psoriasis, and a distinct selectivity profile that warrants further investigation.

Funding Source(s): Bristol-Myers Squibb

\section{COMORBIDITY IN SYSTEMIC LUPUS ERYTHEMATOSUS}

${ }^{1}$ Bugra Egeli*, ${ }^{1}$ Asli Ece Soykut, ${ }^{2}$ Serdal Ugurlu. ${ }^{1}$ stanbul University-Cerrahpasa, Cerrahpasa Medical Faculty; ${ }^{2}$ Division of Rheumatology, Department of Internal Medicine, Cerrahpasa Medical Faculty, Istanbul University-Cerrahpasa

10.1136/lupus-2019-Ism.226
Abstract 226 Table 1 Prognostic factors of SLE patients in 2009 and 2018

\begin{tabular}{|c|c|c|c|}
\hline & $2009, n(\%)$ & $2018, n(\%)$ & $p$ value \\
\hline Age & $41 \pm 7$ & $53 \pm 8.76$ & \\
\hline AMI/Stroke & $\mathrm{n} / \mathrm{a}$ & 10 (15.38) & $\mathrm{n} / \mathrm{a}$ \\
\hline Cancer & $\mathrm{n} / \mathrm{a}$ & $2(3.08)$ & $\mathrm{n} / \mathrm{a}$ \\
\hline Diabetes & $2(2.13)$ & 8 (12.31) & 0.009 \\
\hline Hypertension & $33(35.11)$ & 37 (56.92) & 0.006 \\
\hline Angina & $\mathrm{n} / \mathrm{a}$ & $16(26.23)$ & $\mathrm{n} / \mathrm{a}$ \\
\hline Total & 94 & 65 & \\
\hline
\end{tabular}

Background In Systemic Lupus Erythematosus (SLE), cardiovascular mortality is important. In our previous study, we observed atherosclerotic plaque formation in carotid and/or femoral artery in SLE patients. ${ }^{1}$ The aim of this study was to assess the comorbidity of the patients diagnosed with SLE over 10 years.

Methods The sample group is a subset of 2009 study. In 2009 , the patients who already had myocardial infarction or cancer diagnosis were excluded. The patients were interviewed with polar questions of whether they were diagnosed with acute myocardial infarction (AMI), cerebrovascular events, cancer, diabetes, and hypertension.

Results We studied 65 patients $(56 \mathrm{~F}, 9 \mathrm{M}$; mean age: 53 $\pm 8.76)$ with SLE diagnosis.

In 2009, out of 94 SLE patients we included in the study, $2(2.13 \%)$ of the patients were diagnosed with diabetes, and $33(35.11 \%)$ with hypertension. However, in 2018, out of the 65 patients we reached, $8(12.31 \%)$ with diabetes, and 37 $(56.92 \%)$ with hypertension. The increase in diabetes and hypertension was found significant. $(p=0.009$ and 0.006$)$ The table 1 shows the percentages of newly occurred cancer, angina pectoris, and AMI/Stroke events.

Conclusions In 10 year follow-up, the significant increase in hypertension and diabetes can show us a sign of atherosclerotic plaque formation. However, the increased hypertension and diabetes ratio can still be due to increased age.

Funding Source(s): None

\section{REFERENCE}

1. Ugurlu S, Seyahi E, Cetinkaya F, Ozbakir F, Balci H, Ozdogan H. Intima-media thickening in patients with familial Mediterranean fever. Rheumatology (Oxford). 2009 August;48(8):911-5.

\section{THE LUPUS SEVERITY INDEX ACCURATELY IDENTIFIES PATIENTS WITH SEVERE SLE IN A MULTI-ETHNIC COHORT}

${ }^{1}$ Christine Peschken* ${ }^{2}{ }^{2}$ Carol Hitchon, ${ }^{2}$ David Robinson, ${ }^{2}$ Annaliese Tisseverasinghe, ${ }^{2} \mathrm{Hani}$ El-Gabalawy. ${ }^{1}$ Faculty of Medicine, Department of Internal Medicine, University of Manitoba; ${ }^{2}$ University of Manitoba

\subsection{6/lupus-2019-Ism.227}

Background The Lupus Severity Index (LSI) ${ }^{1}$ proposes to stratify patients by disease severity for clinical research. The LSI ranges from $0-10$, is calculated using ACR classification criteria (ACRc) and demonstrated high predictive accuracy for severity anchored to major immunosuppressive drug use. 